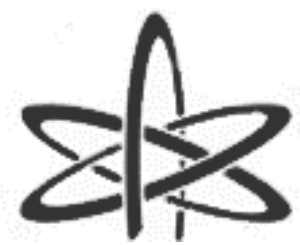

BJRS
BRAZILIAN JOURNAL

$\mathrm{OF}$

RADIATION SCIENCES

08-01 (2020) 01-12

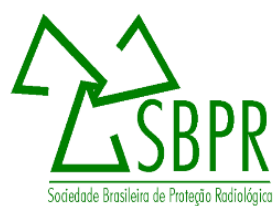

\title{
5X5 Rod Bundle Flow Field Measurements Downstream a
}

\section{PWR Spacer Grid}

\author{
H. F. P. Castro ${ }^{\text {a; }}$ V. Vasconcelos ${ }^{\text {b }}$ A. A. C. Santos ${ }^{\text {b }}$ M. A. F. Veloso ${ }^{a}$ \\ ${ }^{a}$ Universidade Federal de Minas Gerais/Departmentamento de Engenharia Nuclear, CEP: 31270-901, Belo Horizonte, \\ Minas Gerais, Brazil \\ ${ }^{b}$ Centro de Desenvolvimento da Tecnologia Nuclear/Laboratório de Termo-hidráulica, CEP: 31270-901, Belo Horizon- \\ te, Minas Gerais, Brazil \\ higorfabiano@gmail.com
}

\begin{abstract}
The spacer grids are structures present in nuclear fuel assembly of Pressurized Water Reactors (PWR). They play an important structural role and also assist in heat removal through the assembly by promoting increased turbulence of the flow. Understanding the flow dynamics downstream the spacer grid is paramount for fuel element design and analysis. This paper presents water flow velocity profiles measurements downstream a spacer grid in a $5 \times 5$ rod bundle test rig with the objective of highlighting important fluid dynamic behavior near the grid and supplying data for CFD simulation validation. These velocity profiles were obtained at two different heights downstream the spacer grid using a LDV (Laser Doppler Velocimetry) through the top of test rig. The turbulence intensities and patterns of the swirl and cross flow were evaluated. The tests were conducted for Reynolds numbers ranging from $1.8 \times 10^{4}$ to $5.4 \times 10^{4}$. This experimental research was carried out in thermohydraulics laboratory of Nuclear Technology Development Center - CDTN. Results show great repeatability and low uncertainties $(<1.24 \%)$. Details of the flow field show how the mixture and turbulence induced by the spacer grid quickly decays downstream the spacer grid. It is shown that the developed methodology can supply high resolution low uncertainty results that can be used for validation of CFD simulations.
\end{abstract}

Keywords: fuel assembly, spacer grids, PWR, LDV.

ISSN: 2319-0612

Accepted: 2019-10-04 


\section{INTRODUCTION}

The main elements of a nuclear fuel assembly of a Pressurized Water Reactor are the bottom and top nozzles, fuel rods and spacer grids. The water flows axially from the bottom nozzle to the top nozzle, flowing amidst zirconium fuel rods. These rods are kept fixed as a square bundle due to spacer grids. Spacer grids are structures with two main objectives: on one hand they improve the heat exchange by promoting turbulence in the fluid flow due to a local pressure drop. On the other hand, they improve the structural integrity of the fuel assembly helping to keep rods fixed. Therefore it is important to understand the flow dynamics downstream the spacer grids in order to improve its efficiency and safety in PWRs.

During last year several experimental and numerical investigations have been performed. Many of these experimental investigations used 2D or 3D LDV and PIV techniques for axial and lateral velocities profiles measurements.

Chang et al., [1] and Xiong et al., [2] utilized a LDV-2D and 3D, respectively, for axial and lateral velocities profiles evaluation of the water flow through a test rig with a mixing vane spacer grids. An experimental benchmark was presented by Conner et al. [3] whose measurements were made using a PIV-2D Particle Image Velocimetry. The experiments were performed in a $5 \times 5$ rod bundle made of FEP (Fluorinated Ethylene-propylene).

Ylönen [4] brought a novelty when using an ABS (Acrylonitrile Butadiene Styrene) spacer grid. The spacer grid manufactured by Ylönen was based on the spacer grid geometry used by Navarro and Santos [5]. In turn, Navarro and Santos performed numerical simulations of Karoutas et. al. [6] spacer grid. Both Ylönen and Karoutas used numerical simulations to validate their experiments. The aim of this work is to show some important lateral velocities profiles results at downstream of the spacer grid placed in a representative nuclear fuel assembly in a test rig at CDTN ThermalHydraulics Laboratory. 


\section{MATERIALS AND METHODS}

In the Thermal-Hydraulics Laboratory of CDTN (Nuclear Technology Development Center) a series of experiments were carried out. The experiments were run on the Air-Water Circuit - AWC whose water flow regime was carefully monitored under environmental pressure and temperature conditions. Water flow tests were performed for five Reynolds numbers. The RNFA located in the AWC has a 5x5 rod bundle and four spacer grids, similar to a real nuclear fuel assembly. The lateral velocities measurements were carried downstream the spacer grid using a LDV (Laser Doppler Velocimetry). Also, differential pressure transducers were used to measure the pressure differences of the flow in the test section.

\subsection{The air-water circuit}

The tests section contains a $5 \times 5$ square rod bundle flow with 4 spacer grids. Laterally, the tests section has two stainless steel sides and two acrylic sides. Its top is also made of acrylic. These lateral windows and the top of acrylic allow measuring the velocities profiles and also the swirl and crossing flow between sub-channels.

Several measurements have been made for two heights at downstream of a mixing vane spacer grid located in the test section. These measurements have been performed for five different Reynolds numbers between $1,8 \times 10^{4}$ and $5,4 \times 10^{4}$.

The measurements region is shown in Fig. 2. This region was discretized in a set of 506 points of measurement and at each point the $\mathrm{x}$ and $\mathrm{y}$ components were measured. From these data was possible to obtain cross-flow and swirl patterns. A linear sub-set formed by 51 points - in red in Fig. 2 is used to obtain the flow velocity along the sub-channel.

\subsection{The measurements systems}

The lateral velocities profiles were measured by 2D LDV. The LDV technique is based on Doppler Effect. The LDV produces two incident beams of light into the flow. The seeding particles mixed in the water scatter the beam light. The scattered beam light is captured by the photo detector. The difference between the 
scattered light frequency from a moving seeding particle and the emitted beam light frequency is converted in velocities by a signal conditioner and a processor [7].

Some details of the tests section and the measure positions are presented in the Fig.1.

Figure 1: Tests Section
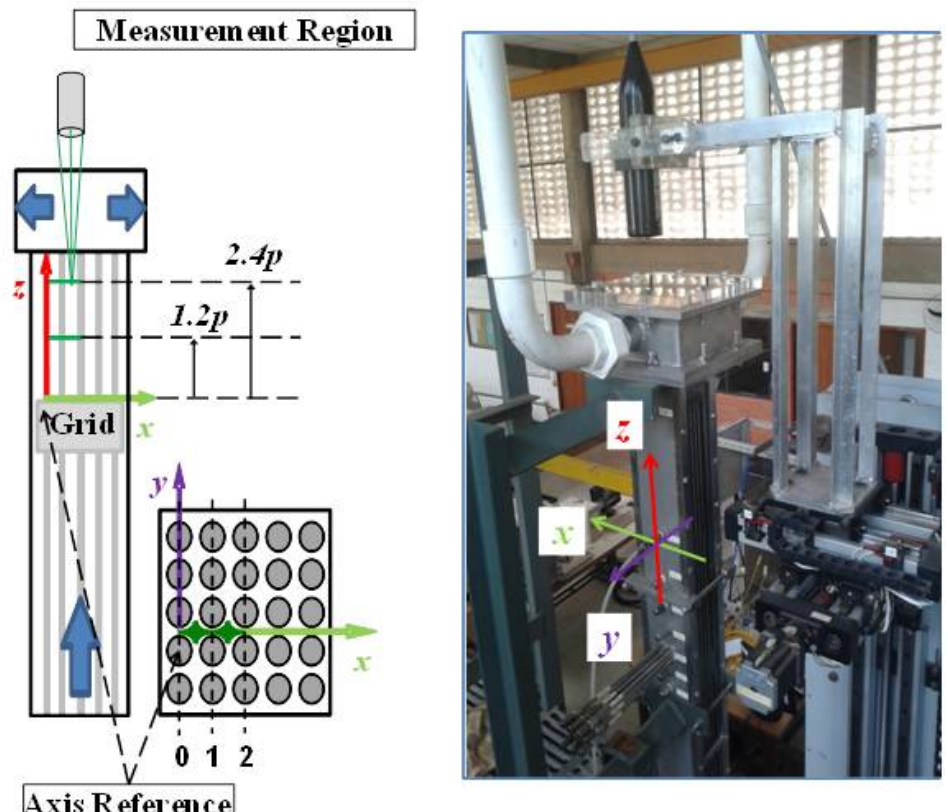

Source: Author

Figure 2: Measurement Region Detail
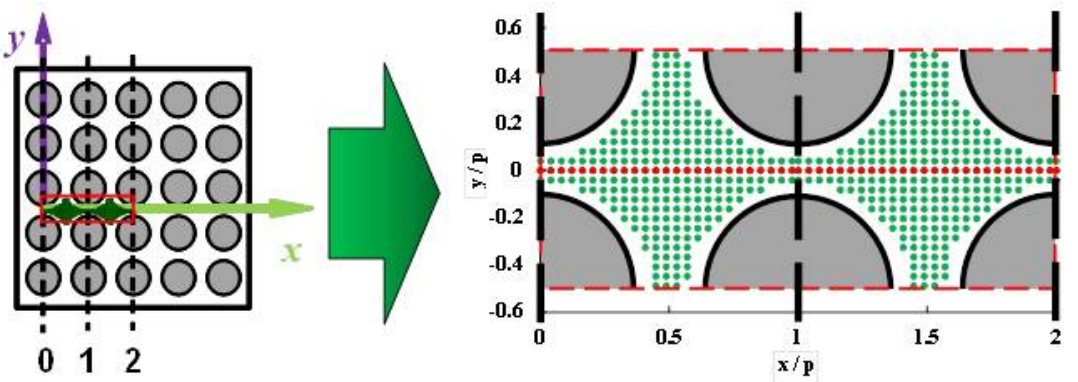

Source: Author

This velocity values are calculated according to equation 1. 


$$
V=\frac{\lambda}{2 \operatorname{sen}(\theta / 2)} f_{D}
$$

Where, $\lambda$ is the wavelength of the laser light, $f_{D}$ is the Doppler-frequency (difference between incident light and scattered light by a moving particle seeding) and $\theta / 2$ is the half angle between incidents light.

The uncertainties associated to the velocity profiles were evaluated with a $95 \%$ confidence interval. Equation 2 shows how these uncertainties were calculated.

$$
u_{v}=\sqrt{\left(\frac{\partial V}{\partial \lambda} u_{\lambda}\right)^{2}+\left(\frac{\partial V}{\partial f_{D}} u_{f_{D}}\right)^{2}+\left(\frac{\partial V}{\partial \theta} u_{\theta}\right)^{2}}
$$

The parameters $u_{\lambda}, u_{f_{D}}, u_{\theta}$ are the uncertainties of wave length, Doppler frequency and angle between two beams, respectively.

The LDV movement trough the measurement points is controlled by an accurate 3D traversing device which gives a high resolution $\left(0.05 \times 10^{-3} \mathrm{~m}\right)$, permitting detailed measurements in the flow.

The mass flow rate at the AWC was determined through an orifice plate (ISO 5167 [8]) which generates a well known pressure drop in this region. Table 1 shows the pressure drop transmitters used in this study. These transmitters have been calibrated by a methodology developed at the Thermalhydraulics laboratory.

Table 1: Pressure drop transmitters.

\begin{tabular}{ccc}
\hline Transmitter & Range $[\mathrm{MPa}]$ & Calibration Uncertainty [kPa] \\
\hline $\mathbf{0}$ & 600 & 3.965 \\
1 & 100 & 0.579 \\
2 & 35 & 0.343 \\
3 & 12 & 0.076 \\
\hline
\end{tabular}


The transmitter 0 was used to monitor the pressure at the test section. A couple of taps were used to pressure drop measurements at the test section region. These measurements were based on the methodology developed by Chun and Oh [9] and In et. al. [10].

Two type $\mathrm{J}$ thermocouples with its transmitters were used to measure temperature at the test section. Each measurement device was calibrated following an established calibration methodology.

The thermocouple operation range is from 0 to $100{ }^{\circ} \mathrm{C}(373 \mathrm{~K})$ and their calibration uncertainty is \pm 0.49 and $\pm 0.47^{\circ} \mathrm{C}$. A K type portable thermocouple was used for environment temperature monitoring. Thermocouple uncertainty is $\pm 2.2^{\circ} \mathrm{C}$.

The signals generated by the data acquisition instrumentation for pressure and temperature measurements were sent to a conditioning board (PCLD-789D with the 50 of gain accuracy $\pm 0,0244 \%$ of the range) and an A/D signal converting (PCL-818HD with 1 from $\pm 0,01 \%$ of the range gain) of the Advantech.

A computer program was developed in order to make real-time data monitoring.

\section{RESULTS AND DISCUSSION}

The experimental conditions were carefully maintained and are presented in Table 2.

Table 2: Experimental conditions.

\begin{tabular}{cccccc}
\hline $\operatorname{Re}\left[10^{3}\right]$ & $\mathrm{U}^{3}\left[\mathbf{1 0}^{3}\right]$ & $\mathrm{T}[\mathrm{K}]$ & $\mathrm{U}[\mathrm{K}]$ & $\mathrm{P}[\mathrm{Pa}]$ & $\mathrm{U}[\mathrm{Pa}]$ \\
\hline 18.29 & $\mathbf{0 . 5 5}$ & $\mathbf{2 9 8 . 3 5}$ & $\mathbf{2 7 4 . 1 5}$ & $\mathbf{6 5 7}$ & $\mathbf{5}$ \\
$\mathbf{2 7 . 5 5}$ & $\mathbf{0 . 8 8}$ & $\mathbf{2 9 8 . 5 5}$ & $\mathbf{2 7 4 . 2 5}$ & $\mathbf{1 0 0 2}$ & 7 \\
36.35 & 1.07 & 298.15 & $\mathbf{2 7 4 . 1 5}$ & $\mathbf{1 4 6 8}$ & 7 \\
45.62 & 1.34 & 298.35 & 274.15 & 2064 & 13 \\
54.12 & 1.63 & 298.45 & 274.25 & 2743 & 29 \\
\hline
\end{tabular}

Fig. 3 shows two graphs for $V_{x}$ and $V_{y}$ velocities profiles in six tests at $1.2 p$ downstream the spacer grid. The plots are for one - Reynolds $=54 \times 10^{3}$ - of five flow conditions. 
Figure 3: Tests repeatability for $R e=54 \times 10^{3}$ and 1.2 height at downstream spacer grid.
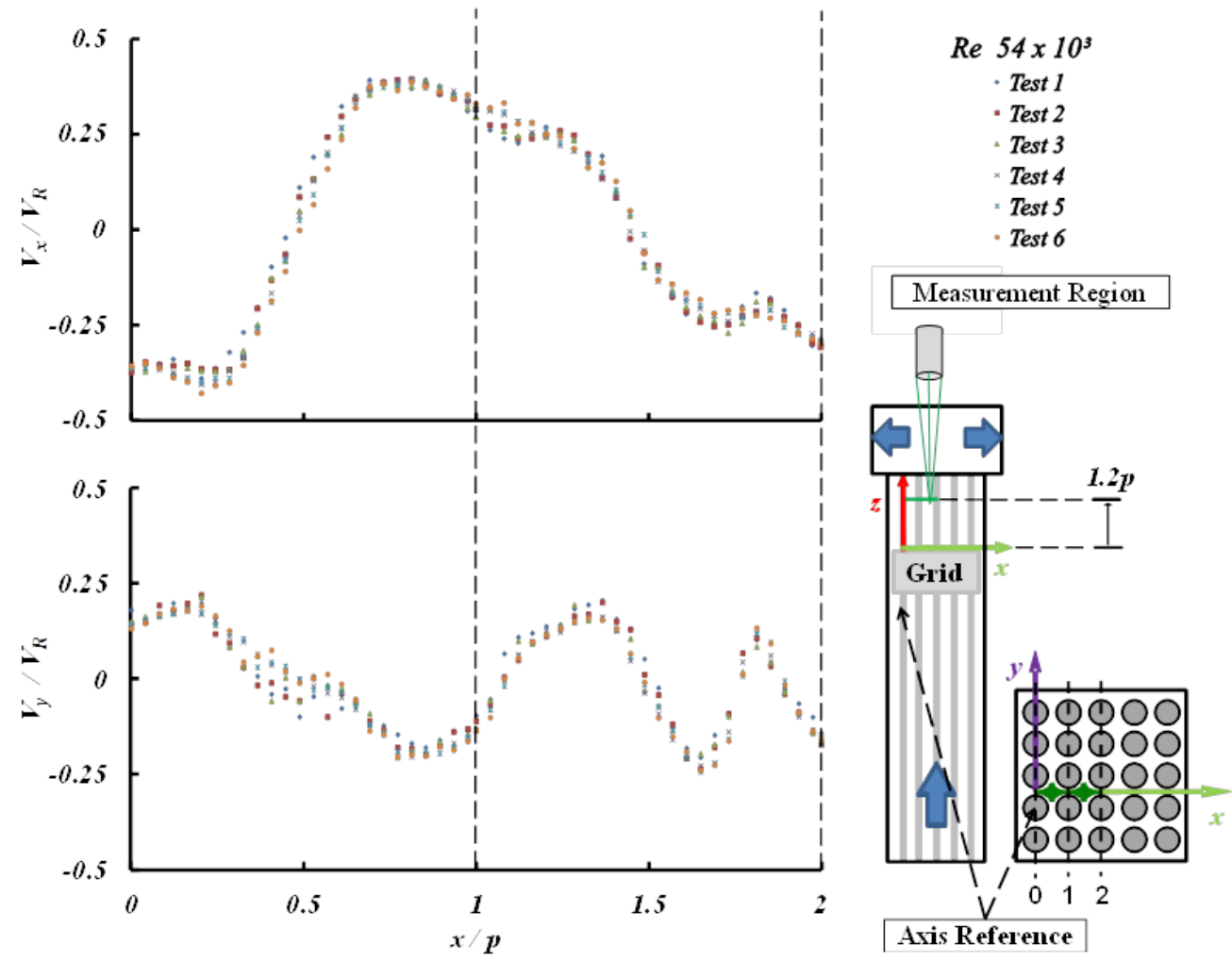

Source: Author

Both graphs in Fig. 3 show a good agreement of measured data. An averaged profile and its uncertainty are shown in Fig. 4.

Fig. 4 presents the whole set of graphics obtained for the averaged lateral velocity downstream the spacer grid for all evaluated flows. Data are normalized by the distance between two consecutive rods $(p)$. The velocity components were also normalized by a reference velocity $\mathrm{V}_{\mathrm{R}}$, the flow averaged velocity, obtained from the Equation 3: 
Figure 4: $V_{x} / V_{R}$ Velocity profile for 1.2 peight at downstream spacer grid (a) and (b). $V_{y} / V_{R}$ Velocity profile for 2.4 p height at downstream spacer grid (c) and (d).

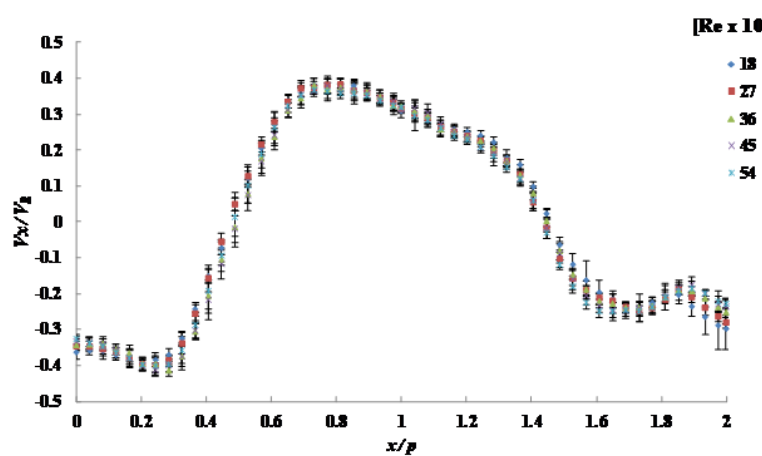

(a)

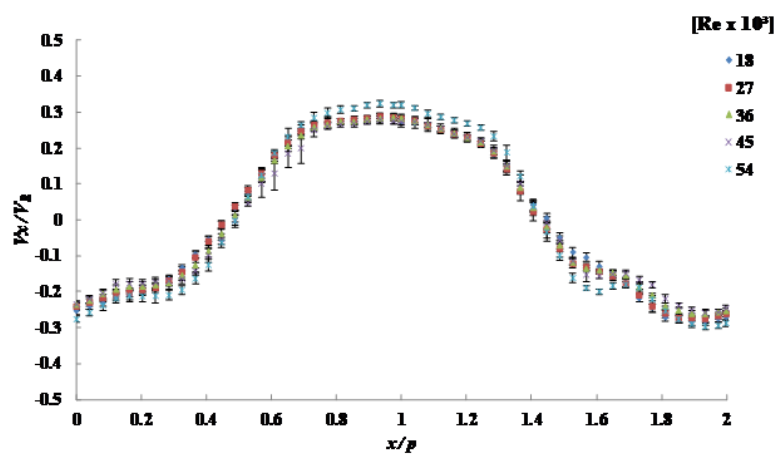

(c)

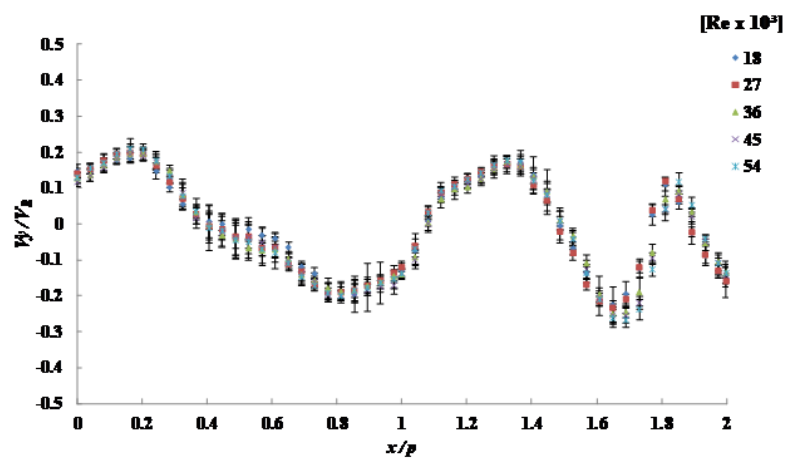

(b)

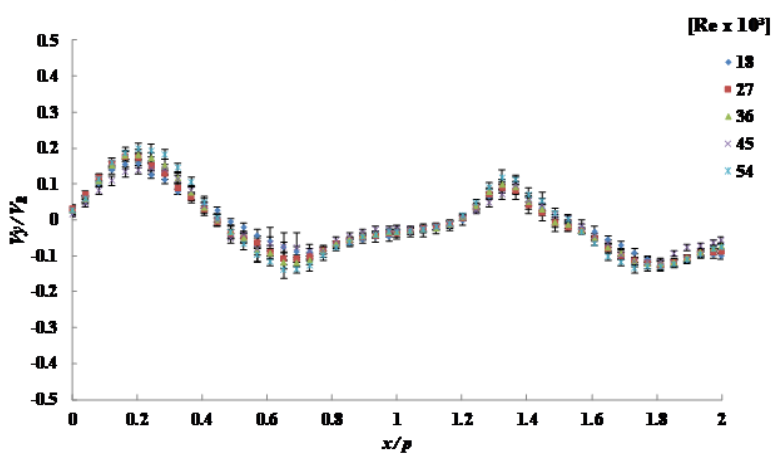

(d)

Source: Author

$$
V_{R}=\frac{\operatorname{Re} \mu}{\rho D_{H}}
$$

Re is the Reynolds number, $\mu$ is the dynamic viscosity of water, $\rho$ is density of water and $D_{H}$ is hydraulic diameter.

The measurement positions along direction $x / p$ in each sub-channel go from 0 to 2 , where $p$ is the pitch. The normalized positions $0 p, 1 p$ and $2 p$ match the center region between the rods.

Still related to Fig. 4 , it is possible to see that both lateral velocity profiles $V_{x} / V_{R}$ and $V_{y} / V_{R}$ had their magnitude reduced as the distance from the spacer grid is increased. Observe also that the velocity profiles have the same behavior for flows with different Reynolds numbers. 
Fig. 5 (a) shows a velocity vector field at height of $1.2 p$ downstream the spacer grid for a flow with Reynolds number of $18 \times 10^{3}$. In Figure 5 (b), a flow with Reynolds number of $54 \times 10^{3}$ is presented at the same conditions.

Figure 5: Velocity profile field for $1.2 \mathrm{p}$ height at downstream spacer grid for Re $=18 \times 10^{3}$ in (a) and for $R e=54 \times 10^{3}$ in (b).

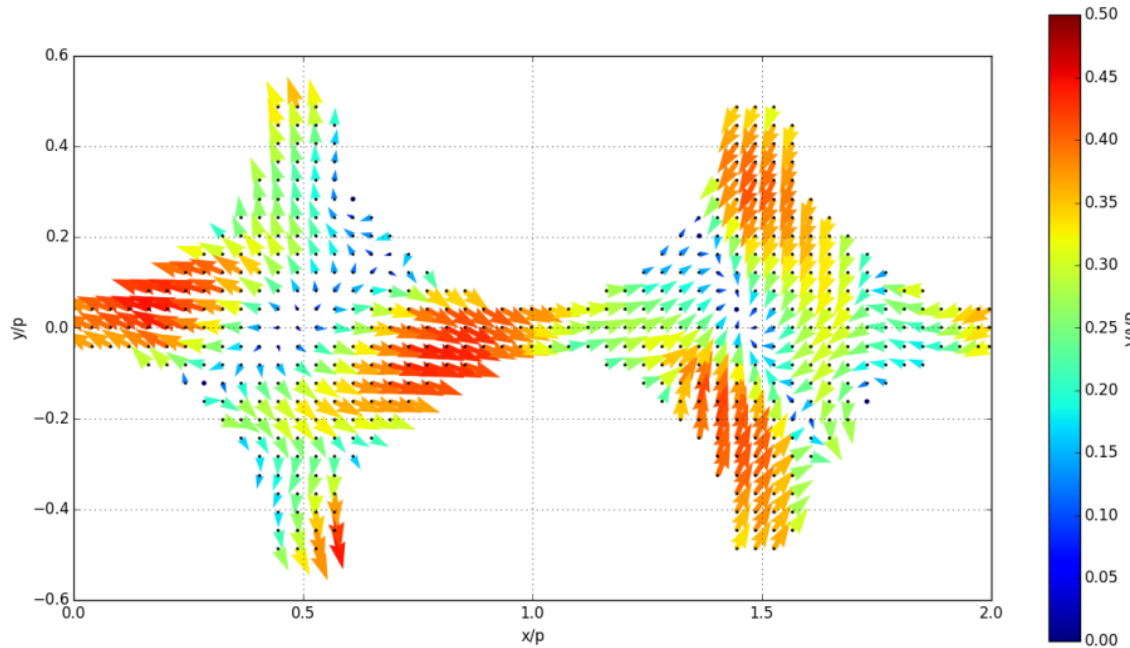

(a)

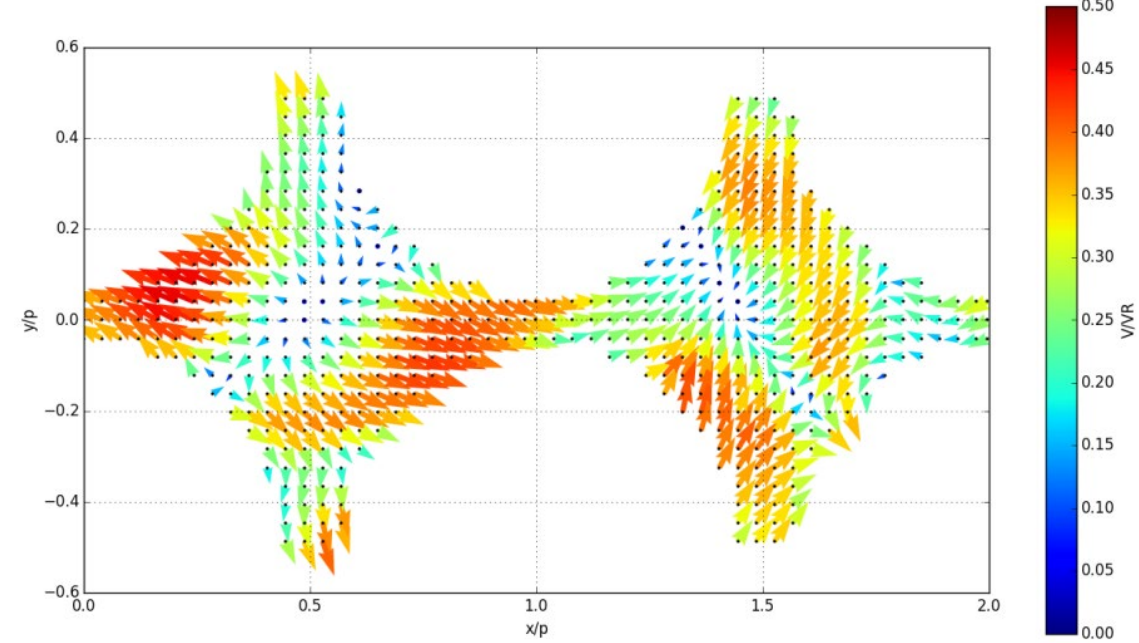

(b)

Source: Author 
Figure 6: Velocity profile field for 2.4 p height at downstream spacer grid for Re $=18 \times 10^{3}$ in (a) and for $\operatorname{Re}=54 \times 10^{3}$ in (b).

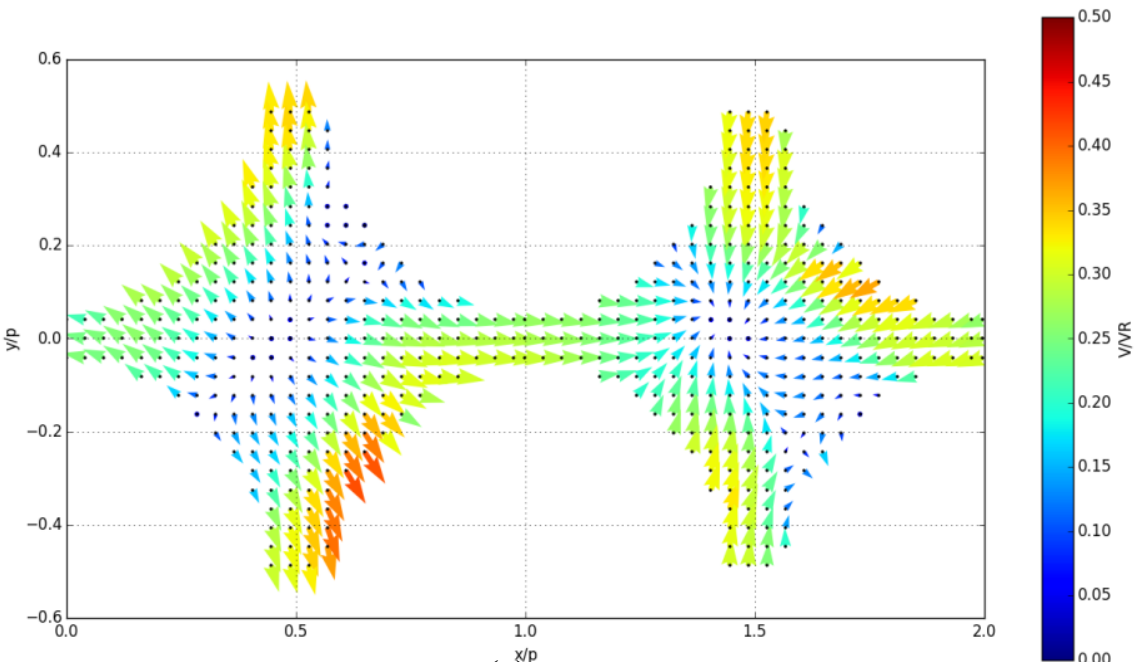

(a)

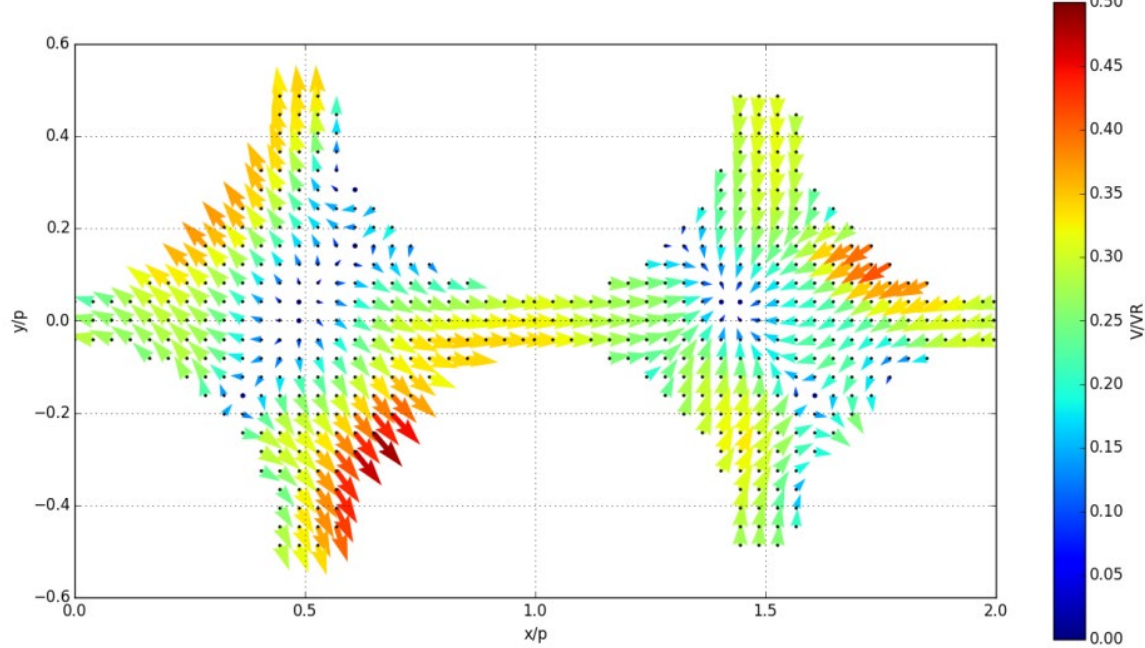

(b)

Source: Author

Graphs presented in Figs. 6 (a) and (b) are similar to those of Fig. 5 (a) and (b). Details of the flow fields show how the mixture and turbulence induced by the spacer grid quickly decays downstream the spacer grid.

The normalized expanded uncertainty for the values of Reynolds between $18 \times 10^{3}$ and $54 \times 10^{3}$ are $0.41 \%$ and $1.24 \%$ respectively. 


\section{CONCLUSION}

In this work was presented results of two lateral velocity profiles downstream spacer grids placed in a representative nuclear fuel assembly in a test rig at CDTN Thermo-Hydraulics Laboratory. From measurements of lateral velocity profiles was possible to obtain two-dimensional velocity vector fields. The measurements were made using the Laser Doppler Velocimetry (LDV) technique.

From the obtained velocity fields it was possible to notice the expected swirl and cross flow patterns. The results obtained from this experimental investigation are useful for CFD validation and as input data for sub-channel analysis codes.

Future work go towards build and test a completely new spacer grid made of ABS by a 3D printer following the methodology used by In et al., [11] e Ylönen [4]. The ABS spacer grid that will be built will be added to the experimental test rig of the AWC circuit of the CDTN ThermalHydraulics laboratory. A model of the new spacer grid geometry will be used to carry simulations using CFD.

\section{ACKNOWLEDGMENT}

This research project has been supported by the following institutions: Universidade Federal de Minas Gerais (UFMG); Centro de Desenvolvimento da Tecnologia Nuclear (CDTN), ; Fundação de Amparo à Pesquisa do Estado de Minas Gerais (FAPEMIG); Conselho Nacional de Desenvolvimento Científico e Tecnológico (CNPq); Indústrias Nucleares do Brasil (INB); e Coordenação de Aperfeiçoamento de Pessoal de Nível Superior (CAPES).

\section{REFERENCES}

1. CHANG, S. K.; KIM, S.; SONG, C. H. Turbulent mixing in a rod bundle with vaned spacer grids. Nuclear Engineering and Design, v. 279, p. 19-36, 2014. 
2. XIONG, J.; YU, Y.; YU, N.; FU, X.; WANG, H.; CHENG, X.; YANG, W. Laser Doppler Measurement and CFD Validation in $3 \times 3$ Bundle Flow. Nuclear Engineering and Design. v. 270, p. 396-403, 2014.

3. CONNER M. E.; DOMINGUEZ O; ELVIS E.; HASSAN Y. A. Hydraulic benchmark data for PWR mixing vane grid. In: INTERNATIONAL TOPICAL MEETING ON NUCLEAR REACTOR THERMAL HYDRAULICS, 2011, Toronto. Annals... Toronto: Canadian Nuclear Society, 2011. p. 25-30.

4. YLÖNEN, A. T. High-resolution flow structure measurements in a rod bundle. Thesis, at the Department of Mechanical and Process Engineering at the ETH, Zürich, Switzerland, 2013.

5. NAVARRO M. A.; SANTOS, A. A. C. Numerical Evaluation of Flow through a $5 \times 5$ PWR Rod Bundle: Effect of the Vane Arrangement in a Spacer Grid. In: INTERNATIONAL NUCLEAR ATLANTIC CONFERENCE, 2009, Rio de Janeiro, Annals... Rio de Janeiro: Comissão Nacional de Energia Nuclear, 2009.

6. KAROUTAS Z.; GU C.; SHOLIN, B. 3-D Flow analyses for design of Nuclear Fuel Spacer. In: INTERNATIONAL TOPICAL MEETING ON NUCLEAR REACTOR THERMAL HYDRAULICS, 1995, Saratoga Springs. Annals... Saratoga Springs: United States Nuclear Regulatory Commission, 1995. p. 3153-3174

7. BSA Flow Software. BSA Flow Software Version 4.10 Instalation \& User's Guide. Dantec Dynamics A/S, Denmark, 2006.

8. ISO - International Organization of Standardization. Measurements of fluid flow by means of pressure differential devices. ISO 5167-1, Geneva: ISO 1991. 33p.

9. CHUN, T. H.; OH, D S. A pressure drop model for spacer grids with and without flow mixing vanes. Journal of Nuclear Science and Technology, v. 35, p. 508-510, 1998.

10. IN, W. K.; OH, D. S.; CHUN, T. H. Empirical and Computational Pressure Drop Correlations for Pressurized Water Reactors Fuel Spacer Grids. Nuclear Technology, v. 139, p. 72$79,2002$.

11. IN W. K.; SHIN C. K.; OH D. S.; CHUN T. H. Experimental Observation and CFD Prediction of Flow Mixing in a Rod Bundle with Mixing-vane Spacer Grid. In: PACIFIC SYMPOSIUM ON FLOW VISUALIZATION AND IMAGE PROCESSING, 2015, Naples, Annals... Naples: Dep. Of Industrial Engineering University of Naples Frederico II, 2015. p. 15-18. 